CANDIDO, Gabriel Cardoso; LEÃO, Hannah de Gregorio; PIRES, Thula Rafaela de Oliveira. "Então não é escravo? É escravo, sim" : uma análise sobre o trabalho escravo contemporâneo a partir do Sul Global.

\title{
"Então não é escravo? É escravo, sim"": uma análise sobre o trabalho escravo contemporâneo a partir do Sul Global
}

"So you're not a slave? Yes, you are a slave": an analysis of contemporary slave labor from the Global South

\section{Thula Rafaela de Oliveira Pires Orientadora \\ thulapires@gmail.com}

Doutora em Direito - PUC-Rio. Mestra em Direito - PUC-Rio. Professora nos cursos de Graduação e Pós-graduação do Departamento de Direito da PUC-Rio. Coordenadora Geral do NIREMA

\section{Gabriel Cardoso Cândido}

gabrielcardosocandido@gmail.com

Discente de Direito na PUC-Rio. Pesquisador do Programa de Educação Tutorial do Departamento de Direito da PUC-Rio.

\section{Hanmah De Gregorio Leão}

hanleone@gmail.com

Discente de Direito na PUC-Rio. Pesquisadora do Programa de Educação Tutorial do Departamento de Direito da PUC-Rio.

\section{Resumo}

O presente trabalho aborda a contemporaneidade do trabalho escravo no Brasil, estabelecendo como pano de fundo a condenação do Estado brasileiro na Corte Interamericana de Direitos Humanos na seara do caso "Fazenda Brasil Verde". Nesse viés, investigam-se as causas da perpetuação do trabalho escravo na sociedade e história brasileiras e seus efeitos nos dias de hoje. Para tanto, as perspectivas jurídicas, históricas e do Sul-Global são os pontos de partida da análise.

Palavras-chave: Escravidão; Fazenda Brasil Verde; racismo; Direitos Humanos; Direito Constitucional.

\section{Abstract}

The present work intends to approach the contemporaneity of slave labor in Brazil, establishing the condemnation of the Brazilian State by the Inter-American Court of Human Rights in the Brasil Verde Fam case as a background. In this sense, it is investigated the causes of perpetuation of slave labor in the Brazilian society and history and its effects nowadays. For that, the legal, historical and South-Global perspectives are the starting points of the analysis. Keywords: Slavery; Brasil Verde Farm; Racism; Human Rights; Constitutional Law.

\footnotetext{
1 Depoimento de Luis Cincinato, vítima de trabalho escravo na Fazenda Brasil Verde (BRASIL REPÓRTER).
} 
CANDIDO, Gabriel Cardoso; LEÃO, Hannah de Gregorio; PIRES, Thula Rafaela de Oliveira. "Então não é escravo? É escravo, sim" : uma análise sobre o trabalho escravo contemporâneo a partir do Sul Global.

\section{Introdução}

Em 2018, o Ministério Público Federal retomou as investigações sobre a incidência de trabalho escravo contemporâneo na Fazenda Brasil Verde, localizada em parte da Amazônia Legal, no estado do Pará, após a condenação do Brasil pela Corte Interamericana de Direitos Humanos (CIDH) com relação ao mesmo caso (MINISTÉRIO PÚBLICO FEDERAL). O país foi denunciado perante a CIDH por causa do atraso da jurisdição nacional para resolvê-lo, sendo que a Corte condenou o Brasil a adotar medidas mais efetivas de combate ao trabalho escravo contemporâneo - como será abordado posteriormente -, fato que gerou a retomada de suas investigações na jurisdição brasileira. Ainda em 2018, como consequência das investigações, o Ministério dos Direitos Humanos publicou o Edital de Convocatória n 3/2017, com o objetivo de buscar e indenizar 67 vítimas de trabalho escravo na Fazenda Brasil Verde (AGÊNCIA BRASIL).

Apesar dos esforços investigativos iniciados no ano de 2018, não foram encontradas notícias de anos posteriores sobre o andamento desses procedimentos. Esse silêncio sobre a Fazenda Brasil Verde traz questionamentos e possíveis respostas para problemas estruturais brasileiros que, até os dias de hoje, continuam sendo ignorados. A partir do referencial determinado pelo caso Fazenda Brasil Verde, pretende-se analisar as incidências, origens e causas de perpetuação do trabalho escravo contemporâneo na sociedade brasileira, adotando-se um ponto de vista jurídico, histórico, crítico e do Sul-Global.

Com esse intuito, este artigo se subdivide em três partes, nas quais se abordará, em primeiro lugar, o contexto histórico e atual do trabalho escravo, do colonial ao contemporâneo, no Brasil. Em seguida, pretende-se analisar a incidência e aplicação histórica do direito internacional, com foco no direito internacional dos direitos humanos, no Brasil, em sua condição histórica de colônia do "Novo Mundo" e local de não ser e não direitos. A última parte do desenvolvimento propõe analisar o constitucionalismo brasileiro enquanto espaço de incorporação das normas de direito internacional, a partir da adoção de direitos humanos enquanto direitos sociais previstos no ordenamento jurídico, questionando sua efetividade na realidade brasileira. A conclusão pretende fundamentar a relação entre combate ao trabalho escravo contemporâneo e direitos humanos, tendo como perspectiva as continuidades entre o passado jurídico e colonial brasileiro e analisando-se, assim, a efetividade dos direitos humanos na jurisdição brasileira. 
CANDIDO, Gabriel Cardoso; LEÃO, Hannah de Gregorio; PIRES, Thula Rafaela de Oliveira. "Então não é escravo? É escravo, sim" : uma análise sobre o trabalho escravo contemporâneo a partir do Sul Global.

Adota-se como dúvida-guia do presente trabalho, o qual se fundamentará em perguntas e não em respostas, em primeiro lugar, quais seriam alguns dos aspectos jurídicos, históricos e estruturais que possibilitam a perpetuação do trabalho escravo colonial nos dias de hoje. Em segundo lugar, se o direito internacional dos direitos humanos, incorporado pelo ordenamento brasileiro constitucionalmente com um caráter fortemente eurocêntrico, conseguiria remediar esse problema intrínseco aos países de passado colonial do Sul-Global.

Os direitos humanos são construídos por dúvidas constantes que os reconstroem, não sendo respostas inflexíveis. Por isso, vale questionar: por que os mecanismos e normas de direitos humanos, adotados constitucionalmente, não conseguem responder à realidade historicamente escravagista brasileira? O questionamento feito por Luis Cincinato, vítima de trabalho escravo na Fazenda Brasil Verde - "Então não é escravo? É escravo, sim.” - evidencia o anacronismo brasileiro: apesar de a Constituição de 1988 garantir inúmeros direitos humanos, as suas violações são a regra estrutural na sociedade brasileira. A condição de escravo é normalizada a ponto de ser invisibilizada, evidenciando a necessidade de Luis Cincinato ter de afirmá-la veementemente.

\section{Trabalho escravo contemporâneo: o caso brasileiro}

As previsões constitucionais e legais que elencam o rol de direitos fundamentais, quando empregadas à realidade brasileira, maculada pelas intensas desigualdades sociais e regionais, mostram-se como assertivas meramente nominais, ou seja, os direitos são vislumbrados e positivados sem que algo seja promovido para efetivá-los. A realização de uma Constituição social, nesse cenário, é enfraquecida por tamanhas incongruências entre classes, pelo racismo, pela cisheteronormatividade compulsória e por outros fatores presentes na realidade brasileira que impedem que o Brasil seja um Estado constitucional verdadeiramente, concedendo ânimo ao texto (CASTRO, 2006, p.141). Persevera-se o desrespeito à existência alheia e à dignidade humana. Vólia Bomfim Cassar, nesse sentido, sintetiza a ideia exposta: “o Brasil ainda não pode ser visto como país que efetivou o welfare (o bem-estar social), pois ainda temos trabalho escravo ou em condição análoga”. (CASSAR, 2018, p.27)

A proibição normativa coibindo o trabalho escravo não constitui um pressuposto de que essa prática não irá se perpetuar, vide a condenação apresentada pela Corte Interamericana de Direitos Humanos ao Brasil, analisada nesta discussão. Salienta-se também que a Constituição de 1824, escravagista, previa, em seu artigo 179, alguns direitos fundamentais, como a 
CANDIDO, Gabriel Cardoso; LEÃO, Hannah de Gregorio; PIRES, Thula Rafaela de Oliveira. "Então não é escravo? É escravo, sim" : uma análise sobre o trabalho escravo contemporâneo a partir do Sul Global.

proibição à tortura e às penas cruéis, bem como a defesa da liberdade e da segurança individual (VILLA, 2011, p.20-3). Entretanto, os destinatários do artigo 179 eram os cidadãos, título esse que não era garantido à população escravizada, fator o qual evidencia que a omissão em relação ao trabalho escravo foi um projeto de poder e manutenção da ordem escravista na Constituição de 1824.

O caso Fazenda Brasil Verde foi apresentado para a Comissão Interamericana de Direitos Humanos no ano de 1998, quando organizações e movimentos sociais realizaram uma denúncia contra o Estado brasileiro "pela sua omissão e negligência em investigar diligentemente a prática de trabalho escravo na Fazenda Brasil Verde, localizada no sul do estado do Pará" (CIDH, 2011, p.1), tendo em vista a obrigação do Estado em garantir, respeitar e proteger os direitos humanos internacionalmente estabelecidos nos tratados internacionais. Tratou-se da quinta condenação do Brasil na Corte Interamericana de Direitos Humanos e a primeira sentença relacionada ao trabalho escravo da Corte, sendo um leading case sobre o tema.

Os trabalhadores que conseguiram fugir afirmaram que havia "a existência de ameaças de morte caso abandonassem a fazenda, o impedimento de saírem livremente, a falta de salário ou a existência de um salário ínfimo, o endividamento com o fazendeiro, a falta de moradia, alimentação e saúde dignas". O Estado brasileiro possuía conhecimento das condições de trabalho da Fazenda desde 1989, porém não fez o necessário para prevenir e condenar as violações, assim como reparar e proteger as vítimas de trabalho escravo na Fazenda. A

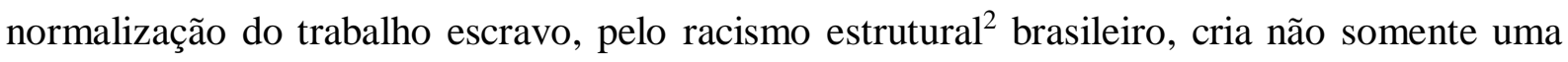
aceitação passiva da sua existência na sociedade, mas ainda perpetua as condições de não sujeitos de sujeitos historicamente desconsiderados, excluídos e invisibilizados.

Vale questionar se as formas de remediação estabelecidas pela CIDH seriam suficientes para o caso brasileiro. Seria realmente o Estado o único ator responsável pelo combate ao trabalho escravo, tendo em vista que, historicamente, os entes privados, incorporados na atuação das Companhias mercantis, tiveram papel essencial para o tráfico de escravos no mundo colonial e, até hoje, os principais casos de trabalho escravo estão relacionados a entes privados? Até os dias de hoje, a resposta pelas violações de direitos humanos cometidas por entes privados, como empresas, é um desafio para o direito internacional dos direitos humanos. (OLIVEIRA, 2018, p.357-58).

\footnotetext{
${ }^{2}$ Entendemos por racismo estrutural "como processo histórico e político, cria as condições sociais para que, direta ou indiretamente, grupos racialmente identificados sejam discriminados de forma sistemática" (ALMEIDA, 2018, p.39).
} 
CANDIDO, Gabriel Cardoso; LEÃO, Hannah de Gregorio; PIRES, Thula Rafaela de Oliveira. "Então não é escravo? É escravo, sim" : uma análise sobre o trabalho escravo contemporâneo a partir do Sul Global.

Entretanto, deve-se compreender que a atuação estatal isolada não é suficiente para combater o racismo estrutural brasileiro, que perpassa entes públicos, privados e os sujeitos clássicos de direito internacional. O Brasil, enquanto colônia de exploração do Novo Mundo, estava definido em um espaço de não direito que possibilitava uma atuação "sem limites" de não sujeitos de direito internacional, como corsários e Companhias, tendo em vista que era um espaço de continuação da guerra europeia fora das normas estabelecidas nos tratados internacionais vigentes em território europeu, ou seja, um Estado de Natureza e arena bélica europeia (SCHMITT, 2014, p.99-100). Dessa forma, uma análise puramente estadocêntrica, herdeira dos moldes eurocentrados de poder, não é suficiente para criar uma efetiva remediação das causas coloniais permanentes de existência do trabalho escravo contemporâneo.

A Comissão Interamericana de Direitos Humanos, no intuito de promover uma análise regional, a partir do Sul Global, contextualiza o caso a partir do histórico brasileiro: o trabalho escravo não é algo pontual, mas um processo contínuo que remonta ao século XV, com a vinda dos europeus para o continente americano e a exploração das populações indígena e negra africana. A análise do caso pressupõe um entendimento da sociedade e história brasileiras para se compreender que o trabalho escravo, no Brasil, foi normalizado historicamente, o que gera resultados até os dias de hoje. Dados apresentados pela Corte, de autoria da OIT, afirmam que, no ano de 2010, 12,3 milhões de indivíduos foram submetidos ao trabalho forçado, sendo 25 mil provenientes do Brasil. Compreende-se, dessa forma, que os mesmos grupos que foram escravizados no Brasil colonial continuam sendo escravos hoje, tendo em vista a colonialidade que marca a história brasileira (PIRES, 2018, p.467).

\section{Existência além da linha (beyond the line) e as fronteiras históricas do Direito}

Fronteiras que delimitam territórios também impõem espaços de direitos. No século XVII, o estabelecimento dos Estados Modernos, solidificados a partir dos Tratados de Westfália, não somente delimitou as novas fronteiras físicas entre as recentes Nações europeias, mas as fronteiras invisíveis divisoras do "Velho" e do "Novo" Mundos. As Linhas de Amizade surgem, então, como uma forma de as Nações Europeias dividirem o mundo entre Europa, ou seja, o mundo onde o Direito positivado (jus gentium) prevalece e é efetivo, e o considerado "Novo Mundo", composto pelas nações não europeias, não cristãs e não brancas, nas quais somente o Direito Natural prevalece, e não o Direito positivado. No "Novo Mundo", o Estado 
CANDIDO, Gabriel Cardoso; LEÃO, Hannah de Gregorio; PIRES, Thula Rafaela de Oliveira. "Então não é escravo? É escravo, sim" : uma análise sobre o trabalho escravo contemporâneo a partir do Sul Global.

de Natureza era a única (des)ordem posta. A teoria de Thomas Hobbes era localizável: o Estado de Natureza não era uma criação imaginária, mas um local pontuado, em que os tratados e o direito positivo não prevaleciam, ou seja, o "Novo Mundo" (SCHMITT, 2014, p.96-100).

Abordar essa questão histórica torna-se tarefa essencial ao se discutir sobre o combate ao trabalho escravo e os direitos trabalhistas no Brasil. Essa Nação, enquanto antigo território do "Novo Mundo", encontra-se em um lugar histórico de não direito. Compreender as atuais violações e retrocessos no campo do trabalho implica não somente analisar as atuais situações sociológicas, sociais, econômicas, raciais, de classe e gênero que compõem a sociedade brasileira, mas analisar o percurso histórico brasileiro, que, desde os primórdios, localizou o Brasil em uma situação de não direito e de não ser que, até hoje, se perpetua.

$\mathrm{O}$ fato de o trabalho escravo ainda ser persistente na sociedade brasileira demonstra que as fronteiras solidificadas no século XVII ainda dividem o mundo do século XXI. O trabalho escravo moderno é a herança do não direito vivenciado e marcado no trabalho escravo africano e indígena dos tempos coloniais. Assim como afirma a professora Thula Pires: "os grupos que foram escravizados, submetidos a relações de servidão, expropriados de sua memória, forma de vida e dignidade, são os mesmos que atualmente continuam sendo alvos das mais variadas formas de representação da violência de Estado e ausentes da representação política do Estado" (PIRES, 2018, p.467).

O estabelecimento de lugares de não direito e de não existência é fundamental para a criação de lugares de direito e de ser. O intelectual Edward Said já afirmava, em sua obra Orientalismo, que o Oriente é uma criação do Ocidente, sendo os dois conceitos antagônicos e, ao mesmo tempo, interdependentes, ou seja, a existência de um implica a existência do outro (SAID, 2008, p.27-9). Questionar esses lugares estabelecidos historicamente significa reanalisar, refundamentar e reconstruir essas construções. As fronteiras entre o trabalho digno e o escravo já foram delimitadas em solo jurídico brasileiro em antigos contextos históricos ainda presentes. Refundar essas fronteiras, a partir do estabelecimento de novos espaços de direitos, antes negados, torna-se função essencial do jurista do Estado de Direito Democrático, consciente de seu passado ainda presente.

Atualmente, o Brasil é considerado um dos países que possui maior incidência de trabalho escravo, sendo condenado pela CIDH por violar a Convenção Americana de Direitos Humanos, aproximadamente quinhentos anos depois de ser "descoberto" enquanto nação na qual os tratados não possuem vigência, mas apenas um direito natural essencialmente eurocêntrico e beligerante. Como compreender a eficácia de implementação de direitos fundamentais 
CANDIDO, Gabriel Cardoso; LEÃO, Hannah de Gregorio; PIRES, Thula Rafaela de Oliveira. "Então não é escravo? É escravo, sim" : uma análise sobre o trabalho escravo contemporâneo a partir do Sul Global.

constitucionais e tratados de direitos humanos em locais nos quais, historicamente, esses espaços de direitos foram negados? Não estaria nessa pergunta a possível resposta para a persistência do trabalho escravo moderno, contrariando tratados de direitos humanos ratificados pelo Brasil e direitos trabalhistas implementados pela Constituição de 1988? A própria história recente do direito internacional do Brasil, tendo em vista a sua ratificação tardia de inúmeros tratados de direitos humanos, demonstra a perpetuação de espaços históricos de não direitos.

A condenação do Estado brasileiro na Corte Interamericana de Direitos Humanos com o caso Fazenda Brasil Verde sentenciou o Brasil pela omissão na prevenção, na punição e na assistência às vítimas, além da morosidade processual e da prescrição, como se pode observar no texto da decisão. A condenação apenas ressaltou a presença do trabalho escravo contemporâneo na realidade brasileira. Dados esses elementos, destaca-se o depoimento de um trabalhador escravizado, em um vídeo produzido pelo projeto "Escravo, nem pensar!":

Eu pensei que não existia trabalho escravo. Cheguei na primeira fazenda, onde houve vários assassinatos. Fui para carvoeira, fazer carvão para a siderúrgica. Ali perto de Açailândia. Outra exploração, também. No tanque, a gente tomava banho, lavava a roupa e bebia água. Barraquinho de lona, não tinha energia. Quebrei um dedo, não fui atendido no hospital. Não me deram medicamento. Retornei pro serviço, o gerente já tinha botado outro no lugar. Só fiz pegar minhas coisas e sair à noite, no beiço da BR. Fui pra outra fazenda pior. A gente foi obrigado a sair fugido. Pra começar, eles só tiram a gente de madrugada. Os caminhões chegam e lotam de gente. Deixam a gente vários dias num hotel, aqueles hotéis feitos de tábua. Dão o almoço, a janta, o café, colocam umas mulheres no meio, mas não dão dinheiro. É muita bebida. Passam a dopar as pessoas só com bebida. Quando a gente pensa que está no bem-bom, os caminhões chegam na madrugada, todo mundo dormindo. Lá a gente compra a foice, compra o esmeril, compra a bota, se não tiver roupa, tem que comprar roupa também. É quando eles colocam no caderno a dívida do hotel. Então, se junta a dívida do hotel, com a dívida do comestível. Quando a gente termina o serviço, não tem saldo. Em todas as cidades onde tu andar aqui no Maranhão, tem gente do trabalho escravo que conseguiu escapar. Que a maioria que não escapa está debaixo do chão. (ESCRAVO, NEM PENSAR)

O testemunho relata as condições degradantes e subumanas trazidas pelos crimes praticados na seara do trabalho escravo contemporâneo. A Convenção Americana de Direitos Humanos $^{3}$ vinculou aos países signatários a proibição expressa à escravidão e à servidão em seu artigo $6^{\circ}$ : "Ninguém deve ser constrangido a executar trabalho forçado ou obrigatório", vedando toda e qualquer forma de tráfico de pessoas. Contudo, a discussão pertinente ao mínimo existencial, à dignidade humana e aos direitos humanos apenas fazem sentido se analisarmos os padrões modernos de humanidade.

\footnotetext{
${ }^{3}$ Ver Pacto Internacional dos Direitos Civis e Políticos - arts.7 e 8, Convenção 29 da Organização Internacional do Trabalho e Convenção 105 da Organização Internacional do Trabalho.

DIGNIDADE RE-VISTA | ISSN2525-698X| 2020 | V. V | N. 10 | Um olhar para a Amazônia: riquezas e

diversidades | Sessão livre. Pastoral Universitária Anchieta PUC-Rio.
} 
CANDIDO, Gabriel Cardoso; LEÃO, Hannah de Gregorio; PIRES, Thula Rafaela de Oliveira. "Então não é escravo? É escravo, sim" : uma análise sobre o trabalho escravo contemporâneo a partir do Sul Global.

A provocação de Douzinas de "Quem são os 'humanos' dos direitos?" é de extrema relevância para a compreensão das hierarquias de humanidade presentes nas relações de poder, de sujeição e de subalternização. O critério "ser humano", embora ideal, não consiste no critério adotado pela modernidade para definir o ser sujeito de direitos humanos (DOUZINAS, s/data). Quem realmente é o sujeito possuidor do direito para pleitear tutelas afetas à existência digna? A proposta do universalismo de direitos pode ser reproduzida a partir de conceitos específicos e restritos de humanidade, tem-se, portanto, que "o padrão de normalização da condição humana eleito pela modernidade se relaciona ao modelo de sujeito soberano de origem europeia, masculino, branco, cristão, heteronormativo (...)” (PIRES, 2017, p.8). A nítida consequência desse perfil estrutural de poder que se formou ao longo do tempo nas relações de trabalho consiste, primordialmente, na subalternidade contínua desses grupos sociais fora da normalização da atribuição de humano. O conceito de humanidade, então, foi calcado em padrões pré-estabelecidos, padrões de gênero, raça, sexualidade, religião, econômico, entre outros, que afastam a maior parte dos indivíduos em prol da sustentação e da perpetuação dos privilégios dos grupos dominantes, mesmo que para tanto haja a anulação de muitas vidas. $\mathrm{O}$ que reconhecemos hoje como direitos humanos não compete aos humanos, mas sim a uma projeção hierarquizada de humanidade. Com o processamento das referidas hierarquias, surgem os seres humanos impróprios à existência, sendo percebidas formas múltiplas, ao longo do tempo, de promover a desumanidade de uns em detrimento da humanidade de outros (DOUZINAS, s/data).

O caso Fazenda Brasil Verde ressaltou um contexto caracterizado pelo trabalho escravo e pela hierarquia de humanidades marcadas pela opressão e pela hostilidade. Os relatos dos sobreviventes resgatados dessa Fazenda ressaltam a extrema degradação humana instaurada nessas relações. Ressaltam-se, então, os depoimentos de Luis Cincinato:

Passei 12 anos no mundo até chegar à (fazenda) Brasil Verde. Lá a gente ficava nas mãos do capataz [fiscal]. Ele fazia com a gente o que queria. Não podia sair de lá. Eles ameaçam: "quem fugir vai chegar em casa com um braço só”. Um cabra como eu, que dá produção no serviço... era para cuidar mais de mim. Sabe o que é acordar todo dia de madrugada e vestir uma roupa molhada para ir para o serviço? As botas molhadas... Era serviço ruim, comida ruim. Então não é escravo? É escravo, sim. (REPÓRTER BRASIL)

\section{De Francisco das Chagas Bastos:}

O mato não era baixo, como tinham prometido. Era um juquirão [mato que cresce no campo] alto, coisa para trator fazer. O capim era maior que nós, e era tão quente que chegava a dar agonia. Um 
CANDIDO, Gabriel Cardoso; LEÃO, Hannah de Gregorio; PIRES, Thula Rafaela de Oliveira. "Então não é escravo? É escravo, sim" : uma análise sobre o trabalho escravo contemporâneo a partir do Sul Global.

dos rapazes que estava com a gente fez a conta: cada um de nós ganhava $\mathrm{R} \$ 0,75$ por dia. Tinha dias que o gato [fiscal] passava debochando. Falava que ali era onde o filho chorava e a mãe não ouvia. Eu ficava mais triste com isso. Um dia, roçando, vi um mato mais baixo. Era um morro de terra, sem verde, sabe? Não podia acreditar, então chamei os outros e perguntei que negócio era aquele ali. Era um tipo... [pausa]. Um tipo não, era o que era: uma sepultura. Na mesma hora um gato [fiscal] veio passando e perguntou: "e aí moçada, como é que tá?" Tomamos coragem para perguntar o que era aquilo. Ele disse que um gato que já trabalhou na fazenda discutiu com um trabalhador e acabou matando o cabra com três tiros. Então, os companheiros do morto enterraram o amigo ali. Nosso medo aumentou. Aquilo podia acontecer com qualquer um de nós. (REPÓRTER BRASIL).

De Raimundo de Macedo:

Da primeira vez, [os fiscais] deixavam a gente queimar as casas de marimbondo - lá tem muito. Numa das vezes, o mato pegou fogo e foi aquela correria. Então, em 2000, o fiscal fazia a gente tirar casa de marimbondo com a mão. Ele falava que se queimasse a fazenda, ia ter que pagar. Doía demais. Nem dava para enxergar direito de tanta picada. Uma coisa horrível. (REPÓRTER BRASIL).

E de Francisco das Chagas da Silva Lira:

Éramos doze. Falei que o cabra estava mal, nem conseguia levantar da rede. Daí o fiscal ficou bravo. Com um pedaço de ferro, pegou uma brasa e partiu para queimar o menino. Eu disse para ele: "Não leve, não. Se levar, você morre." O rapaz já era escravo, ainda ia ser queimado por um tição de fogo? Você não faz isso com ninguém, nem com bicho. Se machucasse um de nós, os outros iam reagir. E eles tinham armas. Ia dar o pior de tudo. Ele deixou a brasa, mas foi até a rede e sacudiu para o cara levantar. (REPÓRTER BRASIL).

Os discursos de sujeitos desumanizados nos fazem refletir sobre a amplitude histórica dos Direitos Humanos e sua incidência na realidade brasileira.

\section{De 1824 a 1988: o trabalho escravo e os direitos humanos no constitucionalismo brasileiro}

Torna-se necessário analisar se o constitucionalismo brasileiro, historicamente, considerou a existência de identidades múltiplas na formação de seu sistema jurídico e constitucional, ou se a referência eurocêntrica sempre foi a regra e régua de direitos, tendo em vista o passado "além da linha" vivenciado pelo "Novo Mundo". A persistência do trabalho escravo contemporâneo no Brasil teria relação com a visão adotada historicamente pelo constitucionalismo brasileiro? Seria essa visão condizente com a formação histórica, social e 
CANDIDO, Gabriel Cardoso; LEÃO, Hannah de Gregorio; PIRES, Thula Rafaela de Oliveira. "Então não é escravo? É escravo, sim" : uma análise sobre o trabalho escravo contemporâneo a partir do Sul Global.

cultural dos países do Cone Sul e, em específico, com as complexidades do passado presente brasileiro? Após essa breve análise, poderá se compreender a efetividade da normativa de direitos humanos, incorporados como direitos sociais na Constituição de 1988.

Em 1824, a Constituição brasileira regulava um sistema imperial. Já em 1891, a Constituição passa a regular um sistema republicano, que também foi implementado pela Constituição de 1988 (VILLA, 2011, p.25-6). Em primeiro lugar, ambos os sistemas imperial e republicano representam formas de governos criados na Europa, frutos das experiências históricas europeias. O imperialismo surge enquanto fruto do absolutismo europeu e forma de governo clássico do surgimento dos Estados Modernos, no século XV. Posteriormente, no século XVIII, a insatisfação com o absolutismo monárquico, culminando na Revolução Francesa, gerou a República enquanto forma de governo mais democrática para os moldes europeus de política iluminista. Dessa forma, compreende-se como as formas clássicas de governo, herdadas do modelo westfaliano de Estado, foram pensadas para uma realidade diversa da brasileira, já que esta não vivenciou os marcos históricos de rupturas europeias.

Assim como ocorreu na adoção das formas de governo no Brasil, os direitos humanos incorporados na Constituição de 1988 também foram compreendidos em uma lógica eurocentrada e não foram repensados e reinterpretados para a realidade específica brasileira. Enquanto a temática do trabalho possui uma grande discussão na Constituição de 1988, sendo citada primeiramente em seu artigo $1^{\circ}$, IV, como integrante do rol de princípios fundamentais da República brasileira e sendo amplamente discutida no capítulo de direitos sociais (art. $6^{\circ}$ a 11), o trabalho escravo somente é citado na Constituição em seu artigo 243 , ao tratar sobre a expropriação de propriedades com exploração de trabalho escravo para a reforma agrária e em seu artigo $5^{\circ}$, XLVII, c, no qual veda a prática. Apesar de a Constituição de 1988 garantir inúmeros direitos para grupos antes invisibilizados na ordem constitucional, como indígenas, que possuem capítulo próprio, e quilombolas, e esses grupos, assim como os trabalhadores, terem tido uma atuação forte e essencial na Assembleia Nacional Constituinte de 1987-88 (COSTA, 2016, p.769), ela apresenta lacunas ao tratar sobre o trabalho escravo e as formas análogas de escravidão.

A concepção de trabalho enquanto direito protetivo decorre das vivências europeias dos séculos XVIII e XIX, na Europa da Revolução Industrial, quando os trabalhadores passaram a protestar contra os maus tratos impostos pelas indústrias (DELGADO, 2019, p.99-100). Assim como no caso do absolutismo monárquico e do Iluminismo, o Brasil não vivenciou uma Revolução Industrial nos moldes europeus, sendo que o trabalho escravo persiste em solo 
CANDIDO, Gabriel Cardoso; LEÃO, Hannah de Gregorio; PIRES, Thula Rafaela de Oliveira. "Então não é escravo? É escravo, sim" : uma análise sobre o trabalho escravo contemporâneo a partir do Sul Global.

brasileiro por mais séculos que o trabalho digno. Ao contrário da Europa, onde os trabalhadores ainda eram considerados humanos, no Brasil, o escravo possui sua existência humana negada, impondo-se as estruturas racistas da zona do não ser.

Não falar dessas estruturas, no Brasil, significa ignorar todas as desigualdades estruturantes que são as causas da continuação do trabalho escravo no Brasil, o que leva à perpetuação do trabalho escravo colonial em forma contemporânea. Dessa forma, abordar somente o direito ao trabalho, no sistema jurídico brasileiro, deixa de considerar uma primeira discussão essencial: a de que existem sujeitos que tiveram suas humanidades negadas para que o trabalho, no Brasil, se perpetuasse em forma de escravidão. Esse silêncio jurídico e social leva à continuação da condição de não sujeitos e à continuidade do trabalho escravo.

Enquanto espaço de incorporação dos direitos humanos como direitos sociais, o ordenamento constitucional brasileiro não apreciou de modo eficaz a aplicação dos tratados de direitos humanos para a realidade específica brasileira, que é diferente dos países do Norte, prejudicando a efetividade desses direitos na sociedade brasileira e agravando os limites do não direito definidos historicamente. Nesse sentido, com relação aos países do Cone Sul, ressaltase a importância não somente dos sistemas constitucionais domésticos, mas do Sistema Interamericano de Direitos Humanos para empreender uma análise dos direitos humanos que seja condizente com as realidades dos países do Sul.

\section{Conclusão}

"Todos os povos são iguais, gozam da mesma dignidade e têm os mesmos direitos. Nada pode justificar a dominação de um povo por outro", diz o artigo 19 da Carta Africana dos Direitos Humanos e dos Povos, que estabelece uma ótica dos direitos humanos "tendo em conta as virtudes das suas tradições históricas e os valores da civilização africana que devem inspirar e caracterizar as suas reflexões sobre a concepção dos direitos humanos e dos povos", a partir da substituição do conceito de indivíduo pelo conceito de povo. A Convenção Americana sobre Direitos Humanos, em seu preâmbulo, não estabelece seu comprometimento em produzir uma leitura do Sul sobre os direitos humanos, por mais que ela seja essencial para se pensar no sistema interamericano de direitos humanos, que foi pensado para as particularidades das inúmeras Américas.

De forma similar, as Constituições brasileiras, em especial a de 1988, não conseguiram determinar os seus direitos humanos de forma a compreender a história e a realidade brasileiras, 
CANDIDO, Gabriel Cardoso; LEÃO, Hannah de Gregorio; PIRES, Thula Rafaela de Oliveira. "Então não é escravo? É escravo, sim" : uma análise sobre o trabalho escravo contemporâneo a partir do Sul Global.

para que as antigas barreiras do não direito impostas no mundo "além da linha" fossem quebradas. Os direitos humanos, enquanto ferramentas essenciais para se alcançar a igualdade material e formal entre mulheres e homens, devem ser pensados de acordo com os pressupostos e bases de cada povo e cultura, para não serem utilizados como formas de dominação de Nações hegemônicas por meio de suas próprias formas de ver direitos que, para muitos povos, não são condizentes com suas realidades. Uma análise do Sul Global dos direitos humanos e da Constituição torna-se necessária para os países do Cone Sul ultrapassarem as barreiras impostas historicamente sobre seus direitos, sendo estes compreendidos enquanto o respeito e a garantia de suas formas originárias de viver, saber e construir, que foram relegadas e violadas pelo eurocentrismo positivado.

O trabalho escravo, enquanto uma das múltiplas afirmações da condição de não direito e de não ser no âmbito do trabalho e da exploração econômica, foi essencial para o estabelecimento dos locais de não ser e não direito históricos no imperialismo colonial e seus efeitos continuam vigentes. Para que o trabalho escravo possa ser realmente combatido, hoje, não basta apenas regular o trabalho digno, mas, antes de tudo, determinar as condições fáticas e jurídicas para que todos os brasileiros sejam considerados sujeitos plenos, independente de etnia, credo, gênero ou escolha sexual, no intuito de construir as bases para se chegar à verdadeira igualdade material, e não apenas a formal já existente. As barreiras históricas são perpetuadas e precisam ser quebradas. Enquanto o racismo não for verdadeiramente combatido e o racismo estrutural continuar a fundamentar as bases da sociedade brasileira, o trabalho escravo colonial continuará a ser contemporâneo.

"Então não é escravo?". Quem sabe, um dia nunca mais. 
CANDIDO, Gabriel Cardoso; LEÃO, Hannah de Gregorio; PIRES, Thula Rafaela de Oliveira. "Então não é escravo? É escravo, sim" : uma análise sobre o trabalho escravo contemporâneo a partir do Sul Global.

\section{Referências bibliográficas}

AGÊNCIA BRASIL. Governo busca vítimas de trabalho escravo da fazenda Brasil Verde. Disponível em: https://agenciabrasil.ebc.com.br/geral/noticia/2018-08/governo-busca-vitimasde-trabalho-escravo-da-fazenda-brasil-verde. Acesso em: 8 abr 2020.

ALMEIDA, Silvio L. de. O que é o racismo estrutural? Belo Horizonte: Letramento, 2018.

CASSAR, Vólia Bomfim. Direito do Trabalho: de acordo com a reforma trabalhista. São Paulo: Método, 2018.

CASTRO, Carlos Roberto Siqueira. Dignidade da pessoa humana: o princípio dos princípios constitucionais. In: SARMENTO, Daniel. GALDINO, Flávio. (Orgs.). Direitos fundamentais: estudos em homenagem ao professor Ricardo Lobo Torres. Rio de Janeiro: Renovar, 2006.

CIDH. Corte Interamericana de Direitos Humanos: Relatório $n^{\circ}$ 169/11 do caso trabalhadores da fazenda Brasil Verde vs. Brasil, 2011. Disponível em: https://www.oas.org/es/ cidh/decisiones/corte/2015/12066FondoPt.pdf. Acesso em: 10 mai 2019.

COSTA, Lucas Nascimento Ferraz. O lobby dos trabalhadores no processo constituinte de 1987-88: um estudo sobre a atuação do DIAP. Estudos Históricos, v.29, n.59, p.767-86, set-dez 2016.

DOUZINAS, Costas. Quem são os 'humanos' dos direitos? Disponível em: http://revolucoes.org.br/v1/sites/default/files/quem_sao_os_humanos_dos_direitos.pdf.

Acesso em: 30 mar 2020.

DELGADO, Mauricio Godinho. Curso de Direito do Trabalho. 18.ed. São Paulo: LTr, 2019.

ESCRAVO NEM PENSAR. Depoimento de um trabalhador escravo. Disponível em: http://escravonempensar.org.br/biblioteca/depoimento-de-um-trabalhador-escravo/. Acesso em: 12 mai 2019.

MINISTÉRIO PÚBLICO FEDERAL. Tribunal manda prosseguir investigação do MPF por trabalho escravo na fazenda Brasil Verde. Disponível em: http://www.mpf.mp.br/regiao1/salade-imprensa/noticias-r1/tribunal-manda-prosseguir-investigacao-do-mpf-por-caso-detrabalho-escravo-na-fazenda-brasil-verde. Acesso em: 8 abr 2020.

OLIVEIRA, Regiane Cristina de. Seeking victims' perspective on remedy: the case of Brasil Verde Farm's workers. Revista Direito GV. São Paulo, v.14, n.2, p.335-66, mai/ago 2018. Disponível em: http://bibliotecadigital.fgv.br/ojs/index.php/revdireitogv/article/ view/77104/73910. Acesso em: 19 abr 2020.

PIRES, Thula Rafaela de Oliveira. 130 anos da Lei Áurea e 30 anos da Constituição de 1988: constitucionalismo e decolonialidade em perspectiva diaspórica. In: GÓES, Luciano (Org.). 130 anos de (des)ilusão, a farsa abolicionista em perspectiva desde olhares marginalizados. Belo Horizonte: Editora D’Plácido, 2018. 
CANDIDO, Gabriel Cardoso; LEÃO, Hannah de Gregorio; PIRES, Thula Rafaela de Oliveira. "Então não é escravo? É escravo, sim" : uma análise sobre o trabalho escravo contemporâneo a partir do Sul Global.

Direitos humanos traduzidos em pretuguês. $13^{\circ}$ Congresso Mundos de Mulheres, 2017. Disponível em: http://www.en.wwc2017.eventos.dype.com.br/resources/anais/1499473935_ ARQUIVO_Texto_completo_MM_FG_ThulaPires.pdf. Acesso em: 13 mai 2019.

REPÓRTER BRASIL. Fazenda Brasil Verde: Histórias de um país que não superou o trabalho escravo. Disponível em: https://reporterbrasil.org.br/brasilverde/depoimentos.html. Acesso em: 8 abr 2020.

SAID, Edward. Orientalismo: o Oriente como invenção do Ocidente. $1^{\text {a }}$ reimpressão. São Paulo: Schwarz, 2008.

SCHMITT, Carl. O nomos da Terra no direito das gentes do jus publicum europaeum. Rio de Janeiro: Editora PUC-Rio, 2014.

VILLA, Marco Antonio. A história das Constituições brasileiras. São Paulo: Leya, 2011. 